\title{
How unemployment insurance savings accounts affect employment duration: evidence from Chile
}

Paula Nagler

Correspondence:

paula.nagler@maastrichtuniversity.nl UNU-MERIT/Maastricht Graduate

School of Governance, Keizer

Karelplein 19,6211 TC Maastricht,

the Netherlands

\begin{abstract}
The introduction of unemployment insurance savings accounts (UISA) in Chile in October 2002 introduced more comprehensive unemployment protection while decreasing the opportunity costs of job change. Being the first to empirically investigate the effect of UISA on employment duration, this paper examines (i) whether the introduction of UISA affected employment duration among formal private sector workers, and (ii) the magnitude of this effect. The analysis is performed on longitudinal social protection data and uses survival analysis techniques, including non-parametric, semi-parametric and parametric analysis, and competing-risk models. The paper finds that workers affiliated to the scheme show an increased hazard ratio of leaving employment, or accelerated time to employment termination. The effect is larger for workers becoming unemployed or inactive compared to workers changing jobs. The results provide strong support that the introduction of UISA led to shorter employment duration and higher mobility of the workforce in Chile.
\end{abstract}

JEL codes: C41, J63, J64, J65

Keywords: Unemployment insurance savings accounts; Employment duration; Survival analysis; Chile

\section{Introduction}

The introduction of unemployment insurance savings accounts (UISA) in October 2002 changed labor market conditions for formal private sector workers in Chile. UISA are individual savings accounts to which employer and employee transfer a share of the worker's salary for possible unemployment spells. Before the introduction, unemployment protection was practically limited to severance pay in case of job termination due to economic necessities of the firm. Additionally, high opportunity costs were involved in job change, and employers had to deal with rigid labor market regulations. After the introduction of UISA, the access to and amount of benefits transferred to workers in case of unemployment or inactivity increased, and opportunity costs of workers changing employment decreased, while ad-hoc obligations of employers to lay off workforce were reduced.

While incentives to leave unemployment have been studied in this context (Reyes, van Ours, \& Vodopivec 2011; Huneeus, Leiva, \& Micco 2012), this study is the first one to my knowledge to empirically investigate the effect of UISA on employment duration. In this paper I fill the gap by using longitudinal social protection data containing information of employment duration of formal private sector workers

C 2013 Nagler; licensee Springer. This is an open access article distributed under the terms of the Creative Commons Attribution License (http://creativecommons.org/licenses/by/2.0), which permits unrestricted use, distribution, and reproduction in any medium, provided the original work is properly cited. 
before and after the introduction of the policy. The paper examines (i) whether the introduction of UISA affected employment duration among formal private sector workers, and (ii) the magnitude of this effect. Following the policy introduction, I expect that workers reacted to the changes by reduced employment duration.

I conduct an empirical analysis using survival analysis techniques to analyze employment duration: in the first part I focus exclusively on the failure of the employment relation: if the current employment relation was terminated, irrespective of the event that follows. In the second part I apply a competing-risk model, where the different following events after employment termination are taken into account.

The results confirm that workers affiliated to the scheme show an increased hazard ratio of leaving employment, or accelerated time to employment termination, suggesting shorter employment duration and higher mobility of the workforce: they have a higher hazard of leaving employment in the Cox model, or accelerated time to failure in the parametric analysis, with this effect being statistically significant throughout the analysis. In the competing-risk analysis, the outcome is equally significant if the following event is a new employment relation or unemployment, and for the final regression model in the case of inactivity. The effect is larger for workers becoming unemployed or inactive compared to workers changing jobs.

The paper is organized as follows: After the introduction, Section 2 describes the Chilean UISA scheme, followed by a literature review on severance pay and labor mobility in Section 3. Section 4 specifies the database used for the analysis, including descriptive statistics of relevant variables. Section 5 describes the method used for the analysis. In Section 6 I apply survival analysis techniques for the empirical analysis and discuss the results: I start with the non-parametric analysis using the Kaplan-Meier estimator, continue with the semi-parametric Cox model and parametric models, before finalizing the analysis with competing-risk models where three different possible endpoints are taken into account. The final section concludes.

\section{The Chilean UISA scheme - context and description}

Before the introduction of UISA, severance pay ${ }^{1}$ was the principal form of unemployment protection in Chile for workers dismissed due to Labor Code $161,{ }^{2}$ complemented by benefits financed by Social Security and additional minor support programs. Severance pay led to a rigid labor market while offering limited protection to unemployed workers, as only workers dismissed due to economic necessities of the firm received benefits during unemployment spells, often without the guarantee of payout ${ }^{3}$. The complementary benefits by Social Security were minimal and independent of previous salaries ${ }^{4}$. Further support for the unemployed was provided through workfare programs for low-income workers, hiring subsidies for firms, unemployment insurance for domestic helpers, and job search assistance (Acevedo, Eskenasi, \& Pagés 2006) ${ }^{5}$.

The political and economic context of UISA introduction was based on two major events: i) the political change in 1990, when democracy was restored in Chile, and center and left-wing parties formed a coalition giving priority to improving workers' position, leading to an extension in severance pay and ii) the sharp increase in the unemployment rate end of the 1990s due to a deterioration in terms of trade and external demand, and the negative impact of the Asian crisis, leaving many workers unemployed and without means to smooth consumption (Acevedo, Eskenasi, \& Pagés 2006). 
The development and design of the new scheme involved various parties with different concerns and interests: while the main governmental concern included the avoidance of moral hazard, employers were worried about labor market flexibility, and workers, represented by labor unions, did not want to give up "hard won rights" as they considered the extension of severance pay after the political change in Chile (Sehnbruch 2004). With the increase in unemployment protection in terms of access to and amount of benefits transferred, while limiting moral hazard through individualized accounts (Reyes, van Ours, \& Vodopivec 2011), and moderately relaxing the severance pay obligations, the new unemployment policy was approved 2001 in Congress with a high political consensus, and subsequently implemented in October 2002 (Acevedo, Eskenasi, \& Pagés 2006).

The new Chilean unemployment protection is based on two components: i) individual savings accounts for each worker that take the form of self-insurance, backed up by ii) a solidarity fund (SF) that functions similarly to an unemployment insurance based on riskpooling. The scheme covers all private sector workers over 18 years of age, with either a permanent or a temporary contract. Enrolment into the new scheme is compulsory for all workers starting a new employment contract after October 2002, therefore avoiding adverse selection. Workers who started a new employment before the introduction date can voluntarily switch to the new system, but only very few decided to do so ${ }^{6}$.

The financing of UISA is regulated differently by contract type. For employees with a permanent contract UISA contributions are financed by both employer and employee (0.6 percent and 2.4 percent, respectively), and are split between the individual accounts to save up for possible unemployment spells of the worker (2.2 percent) and the common SF ( 0.8 percent). The latter is also co-financed by the government with approximately USD 14 million per year (Huneeus, Leiva, \& Micco 2012). For employees with a temporary contract only the employer contributes to the savings account with 3.0 percent and workers do not have access to the $\mathrm{SF}^{7,8}$.

Transfer of benefits was considerably extended in terms of eligibility and total amount transferred. Although the previously existing unemployment subsidy lasting for twelve months was replaced by transfers lasting for a maximum of five months, the current support system is more generous, translating into overall higher transfers. The accumulated benefits in the individual accounts are transferred to workers terminating their employment for any cause, ${ }^{9}$ conditional that they worked for a pre-defined amount of time: six months for workers with temporary contracts and twelve months for workers with permanent contracts, continuous or discontinuous, since they became affiliated to the scheme or since the last time they requested and were granted benefits (Huneeus, Leiva, \& Micco 2012). Workers with permanent contracts losing their job due to Labor Code 161 are equally better protected, as they have, apart from the severance pay and their accumulated savings, access to the solidarity fund in case of low individual savings and therefore access to the insurance component of the scheme. In this case access to the SF is optional, and if workers decide to receive benefits they have to accept additional conditions: i) they have to pay monthly visits to the municipal employment office, ii) they must be willing to join in training programs and iii) they must accept job offers paying at least 50 percent of their pre-unemployment wage (Reyes, van Ours, \& Vodopivec 2011). Finally, workers who do not become unemployed during their working life receive their accumulated account balance when retiring (Sehnbruch 2004). 
Table 1 summarizes the changes in unemployment benefits before and after UISA introduction. For all events (job change, unemployment, inactivity, retirement, and death of the worker) the current situation with UISA is more beneficial for the worker or his/her dependents: for a change in employment, opportunity costs decreased, while in all other cases accumulated savings are directly transferred to the worker or the dependents.

Since the unemployment protection reform, severance pay continues to be paid out in case of dismissal due to economic necessities of the firm, with the possibility of deducting accumulated savings from the severance pay liabilities, equally improving the situation of employers.

\section{Severance pay and labor mobility - what do we know?}

Severance pay is a widespread form of unemployment protection, particularly in developing countries (Vodopivec 2004; 2013) due to large informal labor markets and limited administrative and financial capacities to introduce unemployment insurance (Holzman, Pouget, Vodopivec, \& Weber 2011). Severance pay is however often criticized and considered an inappropriate option for income protection: while severance pay intends to provide compensation for job loss and to stabilize the economy by discouraging layoffs and encouraging long-term work relations, it distorts the behavior of workers and firms, and often provides workers with limited protection during unemployment spells (Feldstein \& Altman 2007; Hopenhayn \& Hatchondo 2012). Labor market distortions are caused by negative effects on both worker accession and separation, and consequently on labor turnover and mobility ${ }^{10}$. Severance pay increases firing costs and reduces consequently the probability that workers become unemployed, but also hinders job creation and prolongs unemployment spells (Blanchard 2000; Nickell 1997). It further decreases the dynamics of structural change due to reduced mobility of the workforce as firms face high payment obligations (Calmfors \& Holmlund 2000). A number of studies additionally confirm the link between higher job security and lower employment levels ${ }^{11,}{ }^{12}$. Limited protection can result through restricted access to severance pay, as workers often face strict regulations of severance pay eligibility, and may involve long judicial processes if firms try to evade their payment obligations. Furthermore firms which are in financial distress or go bankrupt may be unable to transfer the required amount to their previous employees (Acevedo, Eskenasi, \& Pagés 2006).

Table 1 Benefit changes before and after UISA introduction

\begin{tabular}{|c|c|c|}
\hline Event & Before UISA & After UISA \\
\hline Job change & $\begin{array}{l}\text { Loss of accumulated rights to } \\
\text { severance pay }\end{array}$ & $\begin{array}{l}\text { Loss of severance pay (as before), keeps accumulated } \\
\text { savings in UISA account }\end{array}$ \\
\hline \multirow[t]{2}{*}{ Unemployment } & $\begin{array}{l}\text { Severance pay if job loss occurred due } \\
\text { to Labor Code } 161\end{array}$ & \multirow{2}{*}{$\begin{array}{l}\text { Severance pay (as before), transfer of accumulated } \\
\text { savings (maximum five months), solidarity fund } \\
\text {-if applicable }\end{array}$} \\
\hline & All other cases: nothing & \\
\hline \multirow[t]{2}{*}{ Inactivity } & $\begin{array}{l}\text { Severance pay if job loss occurred due } \\
\text { to Labor Code } 161\end{array}$ & \multirow[t]{2}{*}{$\begin{array}{l}\text { Severance pay (as before), transfer of accumulated } \\
\text { savings (maximum five months) }\end{array}$} \\
\hline & All other cases: nothing & \\
\hline Retirement & Nothing & $\begin{array}{l}\text { Transfer of accumulated savings given account } \\
\text { balance is positive }\end{array}$ \\
\hline Death & Nothing & $\begin{array}{l}\text { Transfer of accumulated savings given account } \\
\text { balance is positive to surviving dependents }\end{array}$ \\
\hline
\end{tabular}

Source: by author based on Acevedo, Eskenasi, \& Pagés (2006). 
While unemployment protection through severance pay is widely criticized, some form of unemployment protection can be beneficial not only for the individual worker, but for the economy as a whole. Higher unemployment protection entails, for example, positive outcomes for workers through consumption smoothing and the promotion of higher reemployment stability (Wulfgramm \& Fervers 2013), and for the economy through higher productivity levels (Acemoglu \& Shimer 2000).

In the case of Chile severance pay implied financial support to a restricted group of workers during unemployment spells, as only workers who lost their employment before the expiration of the contractual agreement due to economic or other needs of the firm received benefits. What is more, severance pay obligations did not guarantee the payout of the severance liabilities, as previously explained ${ }^{13}$. In addition, workers lost their accumulated rights to severance pay in case of job change, leading to high opportunity costs: on the one hand due to reduced transfers that are based on tenure in case of job loss, on the other hand due to a more likely lay off during bad economic times, as workers with less tenure are "cheaper" to fire. In the case of Chile Montenegro \& Pagés (2004) show that severance pay resulted in increased protection rights for older and high-skilled workers, while it reduced labor market opportunities for younger and unskilled workers in the period from 1960 to 1998 through the link with tenure.

Empirical papers on the effects of UISA after the transition from severance pay to UISA, and particularly on changes in workers' behavior are still rare and many researchers have relied on simulations instead ${ }^{14}$. One empirical paper by Kugler (2002) documents the transition from severance pay to UISA in Colombia in 1990. Her results show that although UISA partly substitute employer insurance with self-insurance in form of lower wages, the scheme smoothes consumption for the unemployed. The introduction of UISA also reduces distortions in the labor market by increasing both hiring and dismissals, and leads to higher labor mobility.

A number of papers have analyzed the transition in Chile in a more general context: Acevedo, Eskenasi, \& Pagés (2006) discuss the political, social, and economic situation in which this program was implemented and assess the challenges. Sehnbruch (2004) concentrates on embedding the new Chilean unemployment scheme into the context of Latin American labor market legislation, while Sehnbruch (2006) examines how the scheme works in practice and whether it can serve as a model for other emerging and developing economics. Berstein, Fajnzylber, \& Gana (2012) analyze the Chilean UISA scheme as a whole and provide an overview of outcomes and reforms since its implementation. More specific issues have been addressed by Reyes, van Ours, \& Vodopivec (2011) who analyze the job-finding rates of unemployment benefit recipients and Huneeus, Leiva, \& Micco (2012) who look specifically at the change in search efforts of unemployed workers before and after the UISA reform in May 2009.

The effect of UISA on employment duration (and consequently on labor mobility) for Chile is hitherto unclear and provides little evidence: while Berstein, Contreras \& Benvin (2008) show that formal private sector workers value the new unemployment benefits more than its cost, ${ }^{15}$ limited knowledge about UISA and its design could however work against a change in labor mobility (Poblete 2011). A first study by Reyes (2005) on duration of employment contracts using life tables suggests that workers affiliated to UISA show shorter employment duration with 33 percent "surviving" the 
first year of employment, compared to 52 percent for workers not affiliated. The author then focuses on workers below the age of 30 to reduce selection bias and finds that workers affiliated to UISA still show a difference of 7 percentage points compared to workers not affiliated. In his paper the author uses a different database ${ }^{16}$ and concentrates specifically on methodological issues to assess the question.

\section{Database and descriptive statistics}

The panel database used for this analysis is the Chilean EPS database, ${ }^{17}$ a longitudinal survey with questions on the individual and household level about the Chilean labor market and social protection system. The survey was conducted in 2002, 2004, 2006 and 2009 and contains retrospective data since January $1980^{18}$. The first round was conducted in 2002, and was drawn from a frame of 8.1 million current and former members of the Chilean pension system included for at least one month in the timeframe 1980-2001 containing 17,246 individuals, 937 of them reported by surviving relatives. The survey was extended in 2004 with non-participating individuals, completing the base sample, and has been since then representative on the national and regional level for the entire Chilean population. Since 2004 the data is linked to the administrative records of the pension scheme, health insurance, Chile Solidario and other welfare programs. In 2004 new health and wealth questions were added to the questionnaire. In 2006 and 2009 the sample was kept, and includes approximately 16,000 individuals ( 15 years and older) of all regions ${ }^{19}$. The EPS is the first panel survey conducted in Chile with four rounds of data collection covering this range of thematic areas. The questionnaires contain questions on labor history and provisional systems, additional information on education, health, social protection, labor training, property and patrimony, family history and housing.

For the analysis I focus on specific variables of the EPS database: the dependent variable is employment duration for private sector workers measured in months, the main independent variable affiliation to the UISA scheme. I define affiliation to the UISA scheme as follows: I allocate a binary variable UISA $(=0)$ to all employment relations that started during the year before the UISA introduction (October 2001 to September 2002), and I allocate UISA $(=1)$ to all employment relations that started during the year after the UISA introduction (October 2002 to September 2003). As affiliation to the new scheme is mandatory for all private sector workers who started a new employment after the introduction date, I make the assumption that all these workers are affiliated to the scheme ${ }^{20}$. Further explanatory variables included are general information of the worker: gender, age, education, risk aversion, household size, working household members, children, civil status and work related information of the worker: contract type, hours worked per week, monthly net income, firm size, region of employment, and knowledge of UISA ${ }^{21}$.

The additional explanatory variables are defined as follows: gender is coded as female $(=1)$, age is the age of the worker in years. Education is split into four dummy variables: basic education (the reference category), high school, professional formation and higher education (university and higher). Risk aversion was measured by asking survey participants about their individual risk assessment on a scale from 0 (for individuals considering themselves as highly risk averse) to 10 (for individuals stating they are highly disposed to take risk). Household size, working household members and 
children are defined as number of people in the household and working, and number of children in the household. Civil status is defined as married $(=1)$ and includes cohabiting. Contract type is coded as temporary contract $(=1)$, and the variable hours are the average hours worked per week. Income is split into five dummy variables: zero income (the reference category), income up to 100,000 CLP, between 100,000 and 200,000 CLP, between 200,000 and 300,000 CLP, and above 300,000 CLP ${ }^{22}$. Firm size is the number of workers in the firm. Region of work is captured by a binary variable indicating if the worker lives in the metropolitan region of Santiago $(=1)$, and knowledge of UISA $(=1)$ is a self-reported variable of workers indicating if they know or have heard about the new unemployment protection.

The final sample for the analysis consists of 2,323 employment relations composed by formal private sectors workers of 18 years and older who started a new employment during the year before and after UISA introduction. 1,489 employment relations started during the year before the policy introduction (between October 2001 and September 2002), and workers are not affiliated to the UISA scheme ${ }^{23} .834$ employment relations started in the year after the policy introduction (between October 2002 and September 2003), and workers compulsorily joined the new unemployment scheme. As workers can start more than one employment during the two years period, the 2,323 employment relations represent 1,848 single individuals.

Table 2 reports longer employment duration for workers not affiliated to the UISA scheme. This result can, however, be misleading, as these workers started employment in the year before the workers affiliated to the scheme. Additionally, 343 observations are censored, therefore still ongoing at the moment of the last survey round, leading to an expected downward bias of the estimated mean. Some individuals were also observed more than once, if they ended their employment within the considered time frame and started a new employment, and cannot be considered independent observations $^{24}$.

For the competing-risk analysis, I additionally take the following event into account, after finishing the initial employment relation. For workers who ended their employment within the survey rounds, the distribution of the following event is divided into: 798 individuals changed into a new employment, 864 became unemployed, and 318 became inactive. The following event is approximately equally distributed between change in employment, and unemployment with ca. 40 percent each. Slightly more workers face unemployment after terminating their current employment relation, compared to a new employment contract. Inactivity is observed among 16 percent of the workers.

I can observe further characteristics of the following employment relation: among all workers changing into a new employment 85 percent find again a formal employment, slightly more than half (52 percent) find a permanent position, and approximately 82 percent continue as private sector employees. Another 10 percent decide to work on

Table 2 Average employment duration

\begin{tabular}{lrrrrr}
\hline UISA & Months & St. Err. & & [95\% Conf. Interval] & Freq. \\
\hline Before & 31.9 & 0.80 & 30.37 & 33.50 & 1,489 \\
\hline After & 22.8 & 0.87 & 21.04 & 24.47 & 834 \\
\hline Total & 28.6 & & & & 2,323 \\
\hline
\end{tabular}


their own account (self-employed), 3 percent become employers themselves, another 3 percent change into the public sector and the remainder works in the domestic service or as family workers ${ }^{25}$.

\section{Method - survival analysis}

I conduct the analysis using survival analysis techniques, also known as event history or duration analysis. It is defined as the analysis of time until the occurrence of a specific event, from a pre-defined starting point to the transition from one state to another, conditional that it has not yet occurred. In this analysis the time of interest is represented by the duration in one employment relation, the event of interest represented by terminating this employment period. Workers are throughout time "at risk" of terminating employment and experiencing the failure event (Box-Steffensmeier \& Jones 2004).

Survival analysis is different from ordinary least square (OLS) regressions for a number of reasons and requires a special framework: first, the normality distribution of residuals cannot be assumed, as normality of time is unreasonable for many events. The risk of the event occurring is generally not constant over time and almost certainly non-symmetric. Second duration, or time to failure, is always positive. And third it encounters the problem of right censoring: the observed individual participates in the survey, but the event might not have yet occurred when the survey finishes. In my analysis the policy was introduced in October 2002, and the last survey round available records data until early 2010. The workers remaining in their current employment are no longer observed until the following survey round is conducted and published, and are censored. In the analysis I assume non-informative censoring meaning that the censoring time of an individual tells nothing about the risk after that time.

There are three main approaches in survival analysis: non-parametric analysis, the semi-parametric Cox proportional hazards $(\mathrm{PH})$ model and parametric models. While non-parametric and semi-parametric models compare subjects at the time when failures actually occur, parametric models use probabilities that describe what occurs over the whole interval given the information of the subject during time $x_{j}$ (Cleves, Gutierrez, Gould, \& Marchenko 2010). To be more specific: non-parametric analysis assumes no functional form of the survivor function and makes therefore no assumption about the hazard or cumulative hazard, so "letting the data set speak for itself". The effects of additional sets of covariates are not modeled either, and the comparison is performed on a qualitative level. In the semi-parametric Cox model the parametric shape is equally left unspecified, but the model assumes that covariates have proportional baseline hazards. Parametric models are either written in the hazard parameterization, or in the log-time parameterization, also known as accelerated failure time (AFT) metric. All parametric models make assumptions about the shape of the hazard function, with the simplest being the exponential model assuming a constant hazard over time. Further models include Weibull or Gompertz distributions (flat, monotonically increasing or decreasing hazard rates), log-normal and log-logistic models (non-monotonic hazard rates) and the flexible three-parameter generalized gamma distribution (Cleves, Gutierrez, Gould, \& Marchenko 2010).

Estimates are obtained by calculating the maximum likelihood for parametric, and by calculating the partial likelihood for semi-parametric models. Breslow or Efron approximations 
are used to compute the partial likelihood in case failure events are tied in the data set. The maximum likelihood function assuming non-informative censoring includes censored observations with survival time $t_{i}$ and failure indicator $d_{i}$ (taking the value 1 for failures and 0 for censored observations) and has the form

$$
L=\prod_{i=1}^{n} S\left(t_{i} \mid x_{i}, \beta\right) \lambda\left(t_{i} \mid x_{i, \beta}\right)^{d_{i}}
$$

and the partial likelihood with $k$ distinct observed failure times and no ties

$$
L=\prod_{j=1}^{k}\left\{\frac{\exp \left(x_{j} \beta_{x}\right)}{\sum_{i \in R j} \exp \left(x_{j} \beta x\right)}\right\}
$$

(Cleves, Gutierrez, Gould, \& Marchenko 2010) and (Rodríguez 2010).

In a first step, I estimate the survivor function without assuming any particular functional form. The Kaplan-Meier estimator, the non-parametric estimator of the survivor function $S(t)$, estimates the probability of survival past a certain time $t$ and is given by

$$
\hat{S}(t)=\prod_{j \mid t j \leq t} \frac{n_{j}-d_{j}}{n_{j}}
$$

where $n_{j}$ represents the number of individuals at risk at time $t_{j}$ and $d_{j}$ represents the number of failures at time $t_{j}$. This stepwise function shows the survival of workers in their employment, presenting first results of survival between workers who are affiliated to the UISA scheme compared to those who are not.

In a second step, I analyze the survival of employment using the semi-parametric Cox model. The Cox proportional hazards model (Cox 1972) and (Cox 1975) is given by

$$
\lambda\left(\mathrm{t} \mid x_{j}\right)=\lambda_{0}(\mathrm{t}) \exp \left(x_{j} \beta_{x}\right)
$$

where $\lambda_{0}(\mathrm{t})$ is the baseline hazard and $x_{j} \beta_{x}$ the covariates and regression parameters. The baseline hazard is not given a particular parametrization and is left unestimated. The model makes no assumption about the hazard shape over time, but all individuals are assumed to have the same hazard over time, meaning that the hazard rate for any two individuals at any point in time is proportional (Cleves, Gutierrez, Gould, \& Marchenko 2010).

In a third step, I select a functional form for the hazard rate using the Akaike Information Criterion (AIC) and parameterize the shape of the hazard function. Parametric estimations use probabilities that describe the data over the whole time interval given what is known about the observations during this time.

Parametric models are written in two different ways:

in the hazard metric,

$$
h\left(t \mid x_{j}\right)=h_{0}(\mathrm{t}) \exp \left(x_{j} \beta_{x}\right)
$$

or in the log-time metric, also known as the AFT metric,

$$
\operatorname{In}\left(t_{j}\right)=x_{j} \beta_{x}+\epsilon_{j}
$$

Hazard parameterizations can fit exponential, Weibull and Gompertz distributions. Widely used log-time parameterizations are exponential, Weibull, log-normal, 
log-logistic and the generalized gamma distribution (Cleves, Gutierrez, Gould, \& Marchenko 2010).

In a fourth and final step, I apply a competing-risk model to the data, where the endpoint consists of several distinct events and the failure can be attributed to one event exclusively to the others. In a competing risk model I am interested in the causespecific hazard function:

$$
\lambda_{j}(\mathrm{t})=\lim _{\Delta \rightarrow 0+} \frac{P(t \leq T<t+\Delta t \mid T \geq t)}{\Delta t} .
$$

where $\lambda_{j}$ indicates the hazard rate for a single-state process where the hazard rate is subscripted for each of the $j$ events that can occur. To conduct the analysis I censor all events, but the event of interest. Each part of the product can then be estimated separately and I obtain risk-specific hazard rates. As before, I can equally conduct nonparametric, semi-parametric and parametric analysis.

\section{Empirical analysis and results}

The analysis is conducted by dividing the employment relations into two groups: workers who started during the year before UISA introduction and who are not affiliated to the scheme, and workers who started during the year after UISA introduction and had to compulsory join the scheme. This binary variable (UISA =0/1) allows a comparison of employment duration before and after the policy introduction.

The main results of the empirical analysis can be summarized as follows: in the first part of the analysis I focus exclusively on the failure event of terminating the current employment. Affiliation to UISA is significant and increases the hazard of leaving employment, or accelerates time to failure, throughout all regressions irrespective of the method selected or the covariates included in the regressions. In the second part of the analysis, results are qualitatively comparable if the following event is a new employment relation or unemployment: affiliation to UISA is significant throughout all regressions. This is however not the case for workers becoming inactive after terminating their current employment: the difference between both groups is not significant for the Kaplan-Meier estimator, the simple regression or the base specification. Only in the final model UISA affiliation becomes significant. Quantitatively the effect is larger for workers becoming unemployed or inactive, compared to workers changing employment ${ }^{26}$.

\subsection{Non-parametric analysis}

I start the empirical analysis with the Kaplan-Meier (KM) estimator: Figure 1(a) plots the overall Kaplan-Meier survival estimate, and Figure 1(b) the estimates before and after UISA introduction. Figure 1(a) shows a high hazard rate of employment termination during the first year of employment: after approximately twelve months, half of all workers have terminated their current employment contract. From twelve to approximately 45 months another quarter of workers terminate employment. Afterwards the number of surviving workers continues declining in a steady and moderate pace, until the final survey round finishes and approximately 15 percent of the sample is still employed and therefore censored. In Figure 1(b) survival is similar during the first months of employment and starts diverging after approximately ten months, showing higher employment survival for workers not affiliated to the UISA scheme. The logrank 


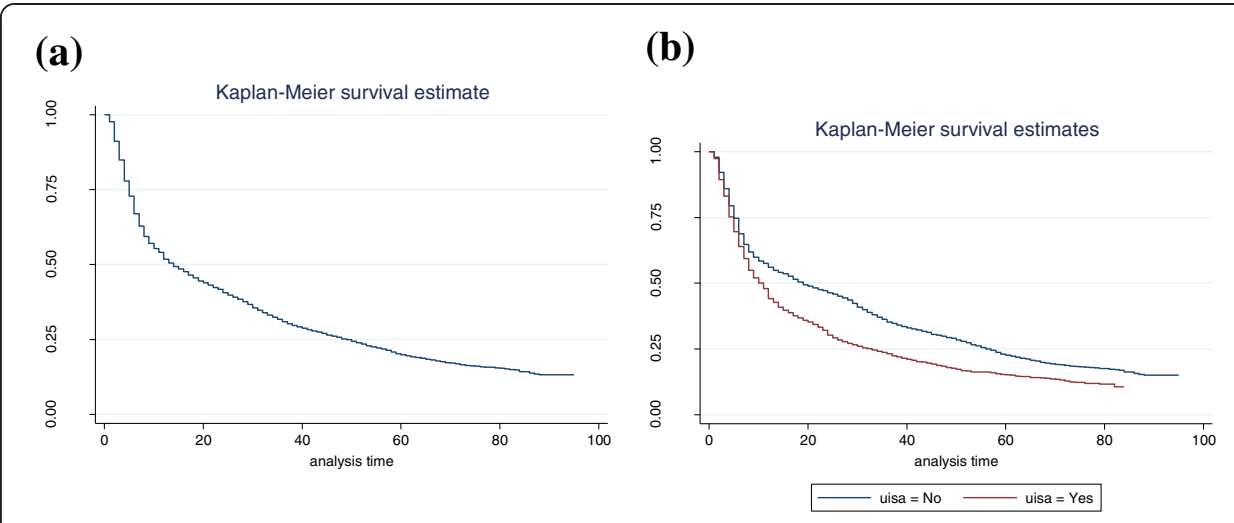

Figure 1 KM survival estimates. (a) overall. (b) before and after UISA introduction.

and the Wilcoxon test confirm that the estimates are significantly different: with a p-value of 0.000 the logrank test rejects the null hypothesis that both estimates are equal and concludes that the difference in employment survival is statistically significant. Returning a p-value of 0.000 , the Wilcoxon result equally rejects the null-hypothesis ${ }^{27}$.

\subsection{Semi-parametric Cox model}

I continue with the simple Cox model, where I regress the main independent variable UISA on employment duration. Regression (1) in Table 3 returns a coefficient of 0.273 . Expressed in hazard rates the hazard of leaving employment is approximately 1.314 times higher for workers affiliated to the UISA scheme (hazard increases by 31.4 percent) and is statistically significant at the 1 percent level.

Next, I test the PH assumption of the simple Cox model. I start with a graphical analysis and plot the hazards of both groups. The hazards are estimated over the range of observed failure times, and all failure times contribute to the estimate of the baseline hazard. The hazard ratios in the figures are approximately proportional ${ }^{28}$. I also conduct a formal test based on Schoenfeld residuals. This test retrieves the residuals, fits a smooth function of time to them, and tests whether there is a relationship. For this test time is $\log$-transformed. The result $\mathrm{p}=0.441$ suggests that there is no evidence of nonproportionality. I do an additional formal test by introducing an interaction between the UISA variable and time. For the test time is log-transformed and the result $(\mathrm{p}=0.427)$ equally suggests that there is no evidence that the UISA effect changes with $\ln ($ time).

I start the multiple Cox regressions by specifying a base specification. I expect the following variables to have an effect on the decision of remaining in employment: gender, age, contract type and education. All variables are statistically significant at the 1 percent level, except for age significant at the 5 percent level. The education dummies are collectively significant at the 1 percent level. While UISA affiliation, female, and a temporary contract increase the hazard of leaving employment, the hazard decreases with age and a higher educational level. With a coefficient of 0.282 the effect of the UISA variable is similar to the simple regression, translating into a hazard ratio of 1.327 , or a 32.7 percent increase in the hazard of terminating employment.

Afterwards I test additional sets of covariates. First I add average net income, total hours worked per week and firm size to capture information on type, place and quality 
Table 3 Regression table Cox model

\begin{tabular}{|c|c|c|c|c|c|c|c|c|c|}
\hline \multirow[t]{2}{*}{ Variable } & (1) & $(2)$ & (3) & (4) & $(5)$ & (6) & (7) & $(8)$ & (9) \\
\hline & \multicolumn{9}{|c|}{ Coefficients } \\
\hline UISA & $0.273^{* * *}$ & $0.282^{* * *}$ & $0.513^{* * *}$ & $0.511^{* * *}$ & $0.539 * * *$ & $0.516^{* * *}$ & $0.517^{* * *}$ & $0.517^{* * *}$ & $0.588^{* * *}$ \\
\hline $\begin{array}{l}\text { - UISA marg. } \\
\text { effect }\end{array}$ & & & & & & & & & $0.491^{* * *}$ \\
\hline Female & & $0.293^{* * *}$ & $0.202^{* * *}$ & $0.212^{* * *}$ & $0.219^{* * *}$ & $0.203^{* * *}$ & $0.201^{* * *}$ & $0.203^{* * *}$ & $0.171^{* * *}$ \\
\hline Age & & $-0.005^{* *}$ & $-0.004^{*}$ & -0.004 & $-0.005^{*}$ & $-0.005^{* *}$ & $-0.005^{* *}$ & $-0.005^{* *}$ & $-0.005^{* *}$ \\
\hline Temp. Contract & & $0.987^{* * *}$ & $0.916^{* * *}$ & $0.912^{* * *}$ & $0.922^{* * *}$ & $0.923^{* * *}$ & $0.912^{* * *}$ & $0.912^{* * *}$ & $0.758^{* * *}$ \\
\hline \multicolumn{10}{|l|}{ Education } \\
\hline - High School & & $-0.207^{* * *}$ & $-0.140^{* *}$ & $-0.149 * *$ & $-0.131^{* *}$ & $-0.147^{* *}$ & $-0.148^{* *}$ & $-0.150^{* *}$ & 0.004 \\
\hline - Prof. Formation & & $-0.238^{* * *}$ & -0.109 & -0.119 & -0.099 & -0.105 & -0.099 & -0.101 & 0.131 \\
\hline $\begin{array}{l}\text { - Univ. and } \\
\text { higher }\end{array}$ & & $-0.444^{* * *}$ & -0.201 & -0.201 & -0.153 & $-0.209^{*}$ & $-0.211^{*}$ & $-0.211^{*}$ & -0.016 \\
\hline Hours & & & $0.007^{* *}$ & $0.007^{* *}$ & $0.008^{* *}$ & $0.007^{* *}$ & $0.007^{* *}$ & $0.007^{* *}$ & $0.007^{* *}$ \\
\hline \multicolumn{10}{|l|}{ Income } \\
\hline - 100,000 CLP & & & 0.073 & 0.066 & 0.062 & 0.084 & 0.066 & 0.067 & 0.085 \\
\hline - 200,000 CLP & & & -0.200 & -0.196 & -0.215 & -0.192 & -0.202 & -0.201 & -0.191 \\
\hline - 300,000 CLP & & & -0.433 & -0.444 & $-0.438^{*}$ & -0.444 & -0.439 & -0.442 & -0.431 \\
\hline$>300,000$ CLP & & & $-0.538^{*}$ & $-0.547^{*}$ & $-0.519^{*}$ & $-0.541^{*}$ & $-0.539^{*}$ & $-0.543^{* *}$ & $-0.540^{*}$ \\
\hline Firm Size & & & 0.000 & & & & & & \\
\hline Risk Aversion & & & & 0.006 & & & & & \\
\hline Household Size & & & & & -0.016 & -0.019 & -0.019 & -0.019 & -0.018 \\
\hline $\begin{array}{l}\text { Working HH } \\
\text { Members }\end{array}$ & & & & & -0.010 & & & & \\
\hline Married & & & & & -0.027 & & & & \\
\hline Children & & & & & 0.028 & & & & \\
\hline $\begin{array}{l}\text { Metropolitan } \\
\text { Region }\end{array}$ & & & & & 0.059 & & & & \\
\hline $\begin{array}{l}\text { Knowledge of } \\
\text { UISA }\end{array}$ & & & & & & 0.028 & & & \\
\hline $\begin{array}{l}\text { UISA } \times \text { Temp } \\
\text { Contract }\end{array}$ & & & & & & & & & $0.380^{* * *}$ \\
\hline $\begin{array}{l}\text { UISA } \times \text { High } \\
\text { School }\end{array}$ & & & & & & & & & $-0.367^{* * *}$ \\
\hline $\begin{array}{l}\text { UISA } \times \text { Prof. } \\
\text { Formation }\end{array}$ & & & & & & & & & $-0.536^{* * *}$ \\
\hline $\begin{array}{l}\text { UISA } \times \text { Univ. } \\
\text { and higher }\end{array}$ & & & & & & & & & $-0.472^{* *}$ \\
\hline Log Likelihood & $-14,022$ & $-13,728$ & $-11,200$ & $-11,199$ & $-10,691$ & $-11,362$ & $-11,362$ & $-11,362$ & $-11,345$ \\
\hline AIC & 28,047 & 27,469 & 22,427 & 22,425 & 21,413 & 22,752 & 22,753 & 22,751 & 22,723 \\
\hline Pseudo R2 & 0.001 & 0.020 & 0.023 & 0.023 & 0.024 & 0.023 & 0.023 & 0.023 & 0.025 \\
\hline $\begin{array}{l}\text { Wald Test } \\
\text { Education }\end{array}$ & & 0.000 & 0.132 & 0.106 & 0.234 & 0.099 & 0.092 & 0.088 & 0.005 \\
\hline $\begin{array}{l}\text { Wald Test } \\
\text { Income }\end{array}$ & & & 0.000 & 0.000 & 0.000 & 0.000 & 0.000 & 0.000 & 0.000 \\
\hline Exit & 1,980 & 1,976 & 1,649 & 1,649 & 1,585 & 1,670 & 1,670 & 1,670 & 1,670 \\
\hline At Risk & 66,530 & 66,484 & 62,479 & 62,586 & 59,108 & 63,427 & 63,427 & 63,427 & 63,427 \\
\hline $\bar{N}$ & 2,323 & 2,319 & 1,982 & 1,981 & 1,899 & 2,006 & 2,006 & 2,006 & 2,006 \\
\hline
\end{tabular}


of work. Second individual risk aversion, third number of household members, working household members, civil status and number of children to capture information on the household composition, fourth region of work, and fifth knowledge of the UISA scheme. Affiliation to UISA, gender, and contract type remain statistically significant throughout all regressions, while age and education vary over the regressions. The coefficient of UISA almost doubles after including the income dummies, increasing the effect of UISA affiliation when income is hold constant. Throughout all regressions, income is collectively significant at the 1 percent level. Hours worked per week is significant at the 5 percent level, while firm size, individual risk aversion, working household members, civil status, number of children, region and knowledge of UISA are not significant. Although household size is not significant in the Cox model, I decide to keep this variable as it returns significant results in other regressions. Regression (8) in Table 3 presents the final Cox model, including all variables of the base specification, hours worked, average net income and household size. The UISA coefficient increases to 0.517 in the final model, translating into a hazard ratio of 1.677 , or a 67.7 percent increase in the hazard of terminating employment when affiliated to the UISA scheme.

Finally, I test a number of interaction terms in regression $(9)^{29}$. The following interaction terms are significant: UISA $\times$ contract type, and UISA $\times$ education dummies. Having a temporary contract and affiliation to the UISA scheme additionally increases the hazard of terminating employment, above and beyond the single effects of the variables. For the other interaction term, UISA $\times$ education dummies, the hazard decreases with higher education if workers are affiliated to the UISA scheme.

Next the PH assumption is tested for the base specification, the final Cox model and the Cox model with interactions. For the Cox model to be valid and to satisfy the $\mathrm{PH}$ assumption, the global $\mathrm{PH}$ test must return p-values above the threshold of 10 percent. The global PH test reports for the three regressions p-values of 0.000 , rejecting the $\mathrm{PH}$ assumption and making the Cox model invalid ${ }^{30}$. While UISA affiliation and education suggest that there is no evidence of non-proportionality in the base specification, gender, age and contract type report p-values below the 10 percent threshold. In the final Cox model various variables have low p-values: UISA affiliation, gender, age, contract type, and the income dummies. The results are similar for the interaction model, except for UISA affiliation and gender, where the p-values are above the threshold value. A stratified Cox model presents a possible solution when certain covariates do not satisfy the PH assumption (Ata \& Sözer 2007).

\section{Stratified Cox model}

Due to the previous results, I relax the assumption that every individual faces the same baseline hazard,

$$
\mathrm{h}\left(\mathrm{t} \mid x_{j}\right)=h_{0}(\mathrm{t}) \exp \left(x_{j} \beta_{x}\right)
$$

in favor of

$$
\begin{aligned}
& \mathrm{h}\left(\mathrm{t} \mid x_{j}\right)=h_{01}(\mathrm{t}) \exp \left(x_{j} \beta_{x}\right), \text { if } j \text { is in group } 1 \\
& \mathrm{~h}\left(\mathrm{t} \mid x_{j}\right)=h_{02}(\mathrm{t}) \exp \left(x_{j} \beta_{x}\right), \text { if } j \text { is in group } 2
\end{aligned}
$$


The baseline hazards can now differ across the levels of stratified variables, but the coefficients $\beta_{x}$ continue to be the same (Cleves, Gutierrez, Gould, \& Marchenko 2010). Covariates returning high p-values are assumed to satisfy the $\mathrm{PH}$ assumption and are included in the model, while covariates that do not fulfill this criterion and report low p-values are stratified (Ata \& Sözer 2007).

I apply the stratified model to the data: after testing different sets of stratified regressions, I stratify contract type in the base specification, and age, contract type and hours in the final model and the interaction model. The global PH tests return a p-value of 0.182 for the base specification, a p-value of 0.813 for the final model and a p-value of 0.717 for the interaction model, rejecting the evidence of non-proportionality. Using the stratified Cox model is therefore more appropriate for the data. The coefficients of UISA affiliation remain similar, suggesting quantitatively comparable effects as in the previous Cox regression Table ${ }^{31}$.

\subsection{Parametric models}

I start the parametric analysis by comparing the six parametric model shapes using the Akaike Information Criterion. The AIC penalizes each model's log likelihood to reflect the number of parameters estimated (Akaike 1974). The preferred model distribution is the one with the lowest AIC value, in my case the generalized gamma distribution. Using this distribution, I run four regressions (simple model, base specification, final model and interaction model) and compare the results in Table 4: the UISA variable is statistically significant at the 1 percent level in all regressions, as well as age, contract type, hours worked and income. In all four regressions the UISA coefficient is negative, implying "accelerated" time to failure. Expressed as time ratios, the simple model returns a value of 0.781 , suggesting that time to failure is approximately 21.9 percent lower compared to workers not affiliated to the scheme. In the base specification time to failure is less accelerated for UISA affiliates with a time ratio of 0.850 . When adding the income variables to the regressions in the final and interaction model, the UISA coefficient value decreases. The results return a time ratio of 0.627 and 0.628 (marginal effect). Education is not significant in the final model, while income is significant at the 1 and 10 percent level in the base specification and the interaction model, respectively. The interaction terms are significant at the 5 percent level, and confirm the previous interpretation: affiliation to the UISA scheme and having a temporary contract additionally accelerate time to failure, while the interaction UISA $\times$ education decelerates time to employment termination. Analyzing the parameters, the special cases of the generalized gamma distribution Weibull $(\kappa=1)$, log-normal $(\kappa=0)$ and the exponential distribution $(\kappa=\sigma=1)$ are not fulfilled.

As a last step in the parametric analysis, I run the final model, and estimate the hazard functions based on the generalized gamma distribution ${ }^{32}$. Figure 2(a) returns the overall hazard, indicating a steep increase in the hazard rate during the first year of employment, with a peak after approximately 12 months, and a steady decline thereafter. Figure 2(b) shows the hazard function before and after UISA introduction, with a considerably higher hazard rate for UISA affiliates, diverging especially during the first two years of employment, and converging over the remaining time. The peak after approximately one year is more pronounced for workers affiliated to UISA. 
Table 4 Generalized gamma regressions

\begin{tabular}{|c|c|c|c|c|}
\hline \multirow[t]{2}{*}{ Variable } & Simple model & Base specification & Final model & Interactions \\
\hline & \multicolumn{4}{|c|}{ Acceleration parameters } \\
\hline UISA & $-0.247^{* * *}$ & $-0.162^{* * *}$ & $-0.467^{* * *}$ & $-0.567^{* * *}$ \\
\hline - UISA marg. effect & & & & $-0.465^{* * *}$ \\
\hline Female & & $-0.239^{* * *}$ & $-0.179^{* * *}$ & $-0.157^{* *}$ \\
\hline Age & & $0.010^{* * *}$ & $0.008^{* * *}$ & $0.009^{* * *}$ \\
\hline Temp. Contract & & $-1.305^{* * *}$ & $-1.203^{* * *}$ & $-1.080^{* * *}$ \\
\hline \multicolumn{5}{|l|}{ Education } \\
\hline - High School & & $0.146^{* *}$ & 0.068 & -0.066 \\
\hline - Prof. Formation & & $0.218^{* *}$ & 0.042 & -0.125 \\
\hline - Univ. and higher & & $0.481^{* * *}$ & 0.141 & -0.017 \\
\hline Hours & & & $-0.011^{* * *}$ & $-0.011^{* * *}$ \\
\hline \multicolumn{5}{|l|}{ Income } \\
\hline - 100,000 CLP & & & 0.095 & 0.133 \\
\hline - 200,000 CLP & & & $0.453^{* *}$ & $0.493^{* *}$ \\
\hline - 300,000 CLP & & & $0.745^{* * *}$ & $0.772^{* * *}$ \\
\hline$>300,000$ CLP & & & $0.901^{* * *}$ & $0.934^{* * *}$ \\
\hline Household Size & & & $0.026^{*}$ & $0.026^{*}$ \\
\hline UISA $\times$ Temp. Contract & & & & $-0.294^{* *}$ \\
\hline UISA $\times$ High School & & & & $0.331^{* * *}$ \\
\hline UISA $\times$ Prof. Formation & & & & $0.422^{* *}$ \\
\hline UISA $\times$ Univ. and higher & & & & 0.398 \\
\hline _const & $2.270^{* * *}$ & $2.919^{* * *}$ & $3.258^{* * *}$ & $3.282^{* * *}$ \\
\hline /n_sig & $0.306^{* * *}$ & $0.221^{* * *}$ & $0.206^{* * *}$ & $0.199^{* * *}$ \\
\hline /kappa & $-0.897^{* * *}$ & $-0.371^{* * *}$ & $-0.235^{* * *}$ & $-0.191^{* *}$ \\
\hline sigma & 1.358 & 1.247 & 1.228 & 1.220 \\
\hline Log Likelihood & $-3,873$ & $-3,575$ & $-3,024$ & $-3,015$ \\
\hline AIC & 7,754 & 7,170 & 6,081 & 6,070 \\
\hline Wald Test Education & & 0.000 & 0.678 & 0.059 \\
\hline Wald Test Income & & & 0.000 & 0.000 \\
\hline Employment Exit & 1,980 & 1,976 & 1,670 & 1,670 \\
\hline At Risk & 66,530 & 66,484 & 63,427 & 63,427 \\
\hline N & 2,323 & 2,319 & 2,006 & 2,006 \\
\hline
\end{tabular}

${ }^{*} p<0.1,{ }^{* *} p<0.05, * * * p<0.01$.

(Std. Err. clustered by ID).

Notes: The coefficients reported in Table 4 are expressed as $\tau_{j}=\exp \left(-x_{j} \beta_{x}\right) t_{j}$ and are called the acceleration parameters. If coefficients are negative, they "accelerate" time, so failure is expected to occur sooner; if coefficients are positive, they "decelerate" time, so failure is expected to occur later. If coefficients are equal to zero, then time passes at its "normal" rate (Cleves, Gutierrez, Gould, \& Marchenko 2010). Another option are exponentiated coefficients, which are interpreted as time ratios.

\subsection{Competing-risk model}

In a competing-risk model the failure event can occur for more than one reason. In this dataset terminating employment can lead to three different events: to another employment contract $\left(T_{1}\right)$, to unemployment $\left(T_{2}\right)$, or to inactivity $\left(T_{3}\right)$. I can equally conduct non-parametric, semi-parametric and parametric analysis. As before, I start with nonparametric Kaplan-Meier estimates, continue with the semi-parametric Cox model and finalize the analysis with fitting parametric models. 

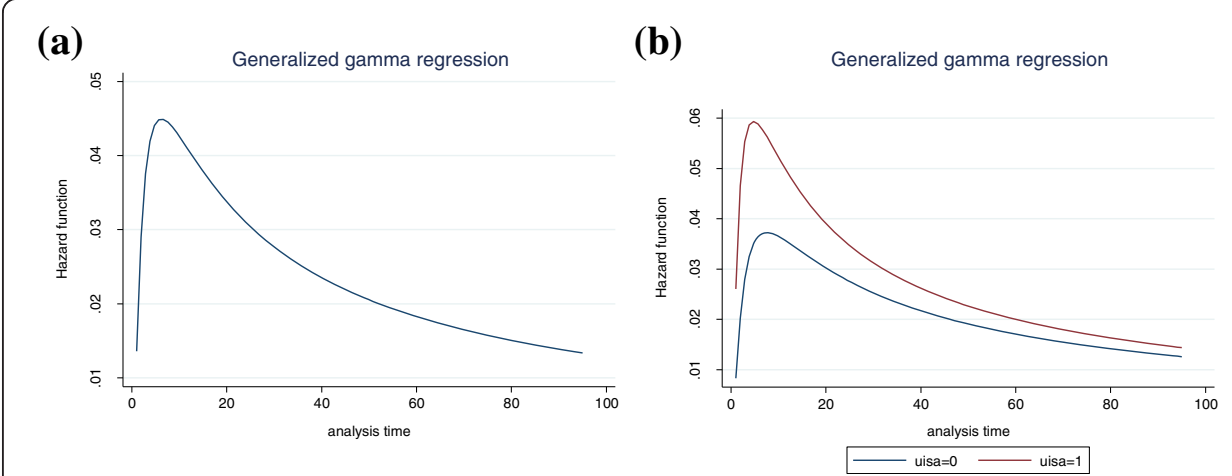

Figure 2 Hazard functions. (a) overall. (b) before and after UISA introduction. Notes: Hazard functions are performed on the final model.

\subsubsection{Non-parametric analysis}

The Kaplan-Meier survival estimates show employment survival before and after UISA introduction in Figure 3 depending on the event that follows the current employment termination. For Figure 3(a) and (b) the logrank and Wilcoxon test return p-values of 0.000, however not for Figure 3(c). For inactivity as the following event, the logrank test returns a p-value of 0.451 , and the Wilcoxon test a p-value of 0.206 , translating into no significant difference between both groups. While UISA affiliation makes a difference if workers change employment or become unemployed, it appears to be irrelevant for workers becoming inactive. In the first two cases the hazard ratio of UISA affiliates is higher compared to the workers not affiliated to the scheme.

\subsubsection{Semi-parametric Cox model}

Based on the regression Table 3 of the semi-parametric analysis, I run the simple regression (1), the base specification (2) and the final model (3) ${ }^{33}$. The results in Table 5 vary depending on the event following employment termination. If workers change their employment, UISA affiliation, gender, and contract type are statistically significant variables, while age, education, hours worked, income and household size do not return significant results. If workers become unemployed all variables are significant at the 1 percent level, except of household size. For the last option, inactivity, the picture changes over the regressions: while UISA affiliation does not return significant results for the simple model and the base specification, it is statistically significant at the 1 percent level in the final model. The remaining variables are significant at the 1 or 5 percent level, except of hours and household size.

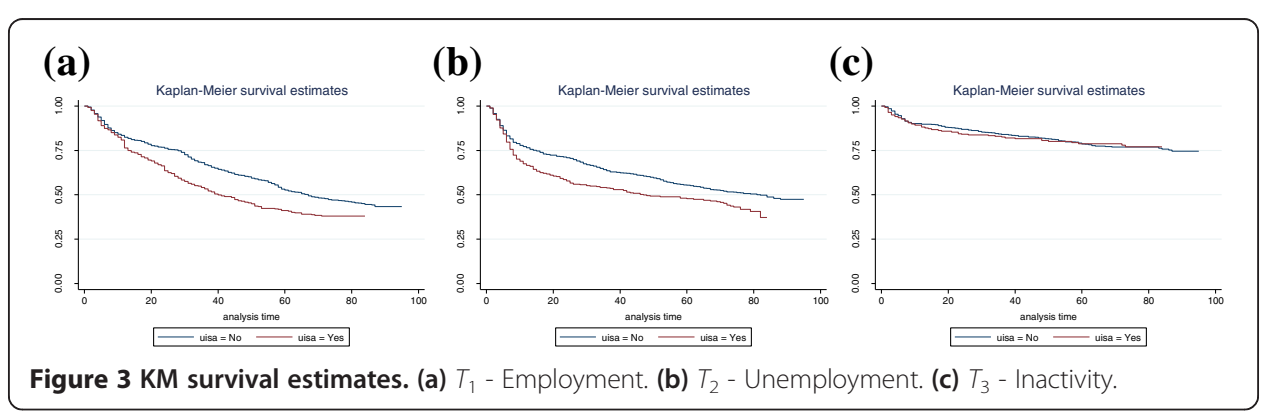


Table 5 Regression table Cox model

\begin{tabular}{|c|c|c|c|c|c|c|c|c|c|}
\hline \multirow[t]{3}{*}{ Variable } & \multicolumn{3}{|c|}{$T_{1}$ - Employment } & \multicolumn{3}{|c|}{$T_{2}$ - Unemployment } & \multicolumn{3}{|c|}{$T_{3}$ - Inactivity } \\
\hline & $(1)$ & $(2)$ & (3) & (1) & (2) & (3) & (1) & (2) & (3) \\
\hline & \multicolumn{9}{|c|}{ Coefficients } \\
\hline UISA & $0.314^{* * *}$ & $0.318^{* * *}$ & $0.375^{* * *}$ & $0.301^{* * *}$ & $0.310^{* * *}$ & $0.645^{* * *}$ & 0.090 & 0.050 & $0.504^{* * *}$ \\
\hline Female & & $-0.275^{* * *}$ & $-0.297^{* * *}$ & & $0.363^{* * *}$ & $0.358^{* * *}$ & & $1.371^{* * *}$ & $1.102^{* * *}$ \\
\hline Age & & -0.004 & -0.004 & & $-0.013^{* * *}$ & $-0.013^{* * *}$ & & $0.012^{* *}$ & $0.013^{*}$ \\
\hline Temp. Contract & & $0.643^{* * *}$ & $0.642^{* * *}$ & & $1.239^{* * *}$ & $1.217^{* * *}$ & & $1.204^{* * *}$ & $0.849^{* * *}$ \\
\hline \multicolumn{10}{|l|}{ Education } \\
\hline - High School & & 0.006 & 0.034 & & $-0.307^{* * *}$ & $-0.276^{* * *}$ & & $-0.379^{* * *}$ & $-0.294^{*}$ \\
\hline - Prof. Formation & & 0.077 & 0.139 & & $-0.671^{* * *}$ & $-0.538^{* * *}$ & & 0.063 & 0.323 \\
\hline $\begin{array}{l}\text { - Univ. and } \\
\text { higher }\end{array}$ & & -0.069 & 0.003 & & $-1.142^{* * *}$ & $-0.803^{* * *}$ & & -0.028 & 0.426 \\
\hline Hours & & & -0.000 & & & $0.015^{* * *}$ & & & 0.005 \\
\hline \multicolumn{10}{|l|}{ Income } \\
\hline - 100,000 CLP & & & -0.303 & & & 0.350 & & & 0.433 \\
\hline - 200,00 CLP & & & $-0.499 *$ & & & 0.149 & & & -0.086 \\
\hline - 300,000 CLP & & & $-0.629^{* *}$ & & & -0.099 & & & -0.819 \\
\hline$>300,000$ CLP & & & $-0.576^{*}$ & & & -0.439 & & & -1.086 \\
\hline Household Size & & & -0.010 & & & -0.024 & & & -0.031 \\
\hline Log Likelihood & $-5,556$ & $-5,510$ & $-5,056$ & $-6,180$ & $-5,940$ & $-4,618$ & $-2,285$ & $-2,160$ & $-1,588$ \\
\hline $\mathrm{AIC}$ & 11,114 & 11,033 & 10,139 & 12,363 & 11,895 & 9,261 & 4,572 & 4,334 & 3,201 \\
\hline Pseudo R2 & 0.002 & 0.010 & 0.012 & 0.001 & 0.035 & 0.045 & 0.000 & 0.055 & 0.056 \\
\hline $\begin{array}{l}\text { Wald Test } \\
\text { Education }\end{array}$ & & 0.859 & 0.804 & & 0.000 & 0.000 & & 0.013 & 0.008 \\
\hline $\begin{array}{l}\text { Wald Test } \\
\text { Income }\end{array}$ & & & 0.112 & & & 0.005 & & & 0.000 \\
\hline $\begin{array}{l}\text { Employment } \\
\text { Exit }\end{array}$ & 798 & 798 & 741 & 864 & 860 & 689 & 318 & 318 & 240 \\
\hline At Risk & 66,530 & 66,484 & 63,427 & 66,530 & 66,484 & 63,427 & 66,530 & 66,484 & 63,427 \\
\hline N & 2,323 & 2,319 & 2,006 & 2,323 & 2,319 & 2,006 & 2,323 & 2,319 & 2,006 \\
\hline
\end{tabular}

${ }^{*} \mathrm{p}<0.1,{ }^{* *} \mathrm{p}<0.05,{ }^{* * *} \mathrm{p}<0.01$.

(Std. Err. adjusted clustered by ID).

Notes: Regressions (1) present the simple model, regressions (2) the base specification, and regressions (3) the final model.

The magnitude of the UISA effect varies according to the next event: ${ }^{34}$ while the coefficient returns a value of 0.375 , translating into a hazard ratio of 1.455 or a 45.5 percent increase in the hazard of terminating employment when the next event is a new employment relation, the coefficient almost doubles to 0.645 , translating into a hazard ratio of 1.906 or a 90.6 percent increase in the hazard of terminating employment when the following event is unemployment. For inactivity as the next event, the coefficient returns a value of 0.504 , or a hazard ratio of 1.655 (65.5 percent increase in the hazard of terminating employment). While UISA affiliation has an effect on the duration of employment in all three cases and increases the hazard of terminating employment, the effect is the highest for workers becoming unemployed. The effect is also higher for inactivity compared to changing employment. A possible explanation could present the direct benefit of receiving the accumulated savings in the case of 
unemployment or inactivity, while a job change does not result in immediate monetary benefits, but reduced opportunity costs.

I test again the $\mathrm{PH}$ assumption, and to consolidate the analysis, I test the assumption for the final model only. None of the regressions fulfill the PH assumption: the values returned for the global $\mathrm{PH}$ test are 0.000 in all cases, suggesting that hazards are nonproportional $^{35}$. Age and contract type are stratified and the global $\mathrm{PH}$ test results suggest that the stratified Cox model is valid in all three cases.

The coefficients of the stratified Cox model return qualitatively and quantitatively comparable results as in Table 5. Irrelevant of the event following employment termination, UISA affiliation is positive and statistically significant at the 1 percent level. Affiliation to the new scheme increases the hazard of workers leaving their current employment and is quantitatively similar to the previous Cox regressions: the hazard of terminating employment increases by 42.6 percent if workers change their employment, by 75.6 percent if workers become unemployed, and by 83.1 percent if workers become inactive ${ }^{36}$.

\subsubsection{Parametric models}

As a last step I fit parametric models and proceed as before. I concentrate on the final model, and test the preferred hazard shape for the different parametric models. The gamma distribution is the preferred model shape for $T_{1}$ and $T_{2}$, and the log-normal distribution for $T_{3}$. As the AIC of the log-normal distribution is only marginally below the AIC of the gamma distribution, I also use the latter shape for $T_{3}$.

In Table 6 all UISA coefficients are statistically significant at the 1 percent level. The UISA coefficients return again considerably lower acceleration parameters for unemployment and inactivity: while UISA affiliation accelerates failure in all cases, the effect is more pronounced if workers become unemployed or inactive after terminating their current employment. The time ratios are 0.705 for employment, 0.563 for unemployment, and 0.535 for inactivity when taking the exponentiated coefficient.

An interesting aspect is the gender coefficient: women have a lower hazard of terminating employment if the following event is a new employment relation, but have an increased hazard of terminating employment if the following event is unemployment, and especially when becoming inactive. Different contribution patterns by women towards household income might present one possible explanation. While a job change can enhance career perspectives and often implies higher earnings, it might be more actively pursued by male workers, still expected to earn the bulk of income within the household. Female employees earn on average 45,000 CLP less compared to male employees in my sample, and female earnings might be seen for many families as an additional contribution to household income, but not as the principal salary. Women are therefore more likely to give up participation in the labor market and become inactive to dedicate more time to family and household labor.

Among the other explanatory variables education is not significant when changing job, it however decelerates time to failure when the following event is unemployment and is significant at the 1 percent level, while the effect is the opposite for inactivity. The variable hour is only significant when the following event is unemployment and accelerates time to failure. Income is significant in all cases and decelerates time to failure with increasing income. Household size is significant at the 10 percent level when becoming unemployed and slightly decelerates time. 
Table 6 Generalized gamma regressions

\begin{tabular}{|c|c|c|c|}
\hline \multirow[t]{2}{*}{ Variable } & $T_{1}$ - Employment & $T_{2}$ - Unemployment & $T_{3}$ - Inactivity \\
\hline & \multicolumn{3}{|c|}{ Acceleration parameters } \\
\hline UISA & $-0.349^{* * *}$ & $-0.575^{* * *}$ & $-0.625^{* * *}$ \\
\hline Female & $0.362^{* * *}$ & $-0.375^{* * *}$ & $-1.234^{* * *}$ \\
\hline Age & 0.006 & $0.013^{* * *}$ & -0.007 \\
\hline Temp. Contract & $-0.966^{* * *}$ & $-1.474^{* * *}$ & $-1.095^{* * *}$ \\
\hline \multicolumn{4}{|l|}{ Education } \\
\hline - High School & -0.103 & $0.194^{*}$ & 0.254 \\
\hline - Prof. Formation & $-0.280^{*}$ & $0.616^{* * *}$ & -0.455 \\
\hline - Univ. and higher & -0.025 & $0.754^{* * *}$ & $-0.712^{* *}$ \\
\hline Hours & -0.002 & $-0.019^{* * *}$ & -0.014 \\
\hline \multicolumn{4}{|l|}{ Income } \\
\hline - 100,000 CLP & $0.484^{*}$ & -0.075 & -0.390 \\
\hline - 200,000 CLP & $0.811^{* * *}$ & 0.178 & 0.294 \\
\hline - 300,000 CLP & $0.980^{* * *}$ & 0.477 & 1.054 \\
\hline$>300,000 \mathrm{CLP}$ & $0.903^{* * *}$ & $0.891^{* *}$ & $1.423^{*}$ \\
\hline Household Size & 0.017 & $0.034^{*}$ & 0.036 \\
\hline _cons & $3.163^{* * *}$ & $4.885^{* * *}$ & $7.109^{* * *}$ \\
\hline /In_sig & $0.497^{* * *}$ & $0.465^{* * *}$ & $0.820^{* * *}$ \\
\hline /kappa & $-0.624^{* * *}$ & -0.209 & -0.410 \\
\hline sigma & 1.644 & 1.592 & 2.270 \\
\hline Log Likelihood & $-1,913$ & $-1,817$ & -876 \\
\hline $\mathrm{AIC}$ & 3,857 & 3,666 & 1,783 \\
\hline Wald Test Education & 0.362 & 0.001 & 0.003 \\
\hline Wald Test Income & 0.002 & 0.001 & 0.000 \\
\hline Employment Exit & 741 & 689 & 240 \\
\hline At Risk & 63,427 & 63,427 & 63,427 \\
\hline N & 2,006 & 2,006 & 2,006 \\
\hline
\end{tabular}

${ }^{*} \mathrm{p}<0.1,{ }^{* *} \mathrm{p}<0.05,{ }^{* * *} \mathrm{p}<0.01$

(Std. Err. adjusted clustered by ID).

Notes: All regressions are based on the final model.

In Figure 4 I compare the hazard functions before and after UISA introduction, and in all cases UISA affiliates have a higher hazard of terminating employment, irrespective of the following event. The shape is comparable, with a steep hazard increase during the first months of employment, a peak after the first year, and a steady decline thereafter.

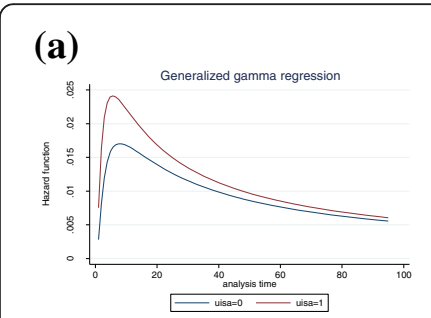

(b)
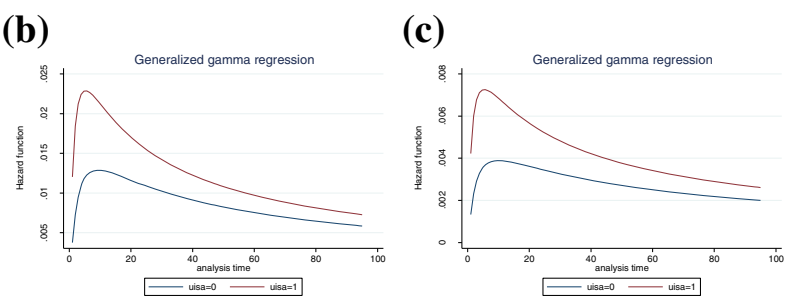

Figure 4 Hazard functions before and after UISA introduction. (a) $T_{1}$ - Employment. (b) $T_{2}$ - Unemployment. (c) $T_{3}$ - Inactivity. Notes: Hazard functions are performed on the final model. 


\subsection{Robustness}

To examine the causal impact I conduct four different falsification tests: first, I simply change the cut-off date from October 2002 to October 2003 "as if" the introduction date began one year later: if this alternative cut-off date is used, the UISA variable is no longer significant when running the same set of regressions. Second, I use an extended time frame including workers who started a new employment during the two years before and the two years after UISA introduction. This sample returns qualitatively the same, and quantitatively similar results as in the one year sample used for the analysis. A more detailed explanation, including regression results, can be found in Additional file 1. Third, I select formal public sector workers as a control group and introduce the UISA variable with the same cut-off date "as if" this group had experienced the policy introduction. In this sample, the UISA variable is not significant, indicating that public sectors employees that were not affected by this policy do indeed not show a significant difference in employment duration. A more detailed explanation can be found in Additional file 1. Fourth and last, I check the unemployment rate in Chile during the year before and after UISA introduction: while the average unemployment rate was 8.4 percent in the year before, it marginally decreased to 8.3 percent in the year after. In the time period Sep-Nov 2001 it amounted to 8.3 percent, during the period Sep-Nov 2002 to 8.5 and during the period Sep-Nov 2003 it slightly decreased to 7.8 percent $^{37}$. Therefore no sharp change in unemployment was experienced during the two year period considered in the analysis.

While these tests give confidence in effectively observing a causal impact of UISA introduction on employment duration, a number of issues remain uncertain: although the policy demands compulsory affiliation to the policy, it is not clear if firms could circumvent affiliation when offering a new employment contract after October 2002. Another aspect is the limited knowledge and use of UISA benefits, as shown by Poblete (2011) in her paper, and might therefore not affect employment duration among workers with no or little knowledge of the new policy. Further aspects to take into consideration are the low benefit transfers, and the one month waiting period to access account savings, that might have little impact on the worker's behavior.

\section{Conclusions}

This paper analyzed the impact of UISA on employment duration in Chile and was motivated by two questions: (i) whether the introduction of UISA has an effect on employment duration and therefore on labor mobility, and (ii) on the magnitude of this effect. Based on my results, I conclude that the introduction of UISA significantly affects employment duration, characterized by an increased hazard ratio of exiting the current employment in the semi-parametric Cox regressions, and by accelerated time to failure in the parametric models. In the remaining section I first summarize the results, before discussing policy implications in the second part.

In the simple Cox regression the hazard is elevated by 31.4 percent for UISA affiliates, while the difference amounts to 67.7 percent in the final model. The results of the stratified models are similar. The parametric models, based on the generalized gamma distribution, return qualitatively the same result: time to failure is accelerated if workers are affiliated to UISA. The time ratio returns a coefficient of 0.627 for UISA affiliates in the final model, suggesting that time to failure is 37.3 percent lower. 
The results of the competing-risk analysis using the final model are summarized as follows: in the Cox model the hazard of leaving employment increases by 45.5 percent if another employment relation follows employment termination, by 90.6 percent if workers become unemployed, and by 65.5 percent if workers become inactive. The parametric generalized gamma regressions return qualitatively comparable results, where time is accelerated for all following events if workers are affiliated to UISA. The time ratios are $0.705,0.563$, and 0.535 , respectively, suggesting that time to failure is 29.5 percent lower for employment and approximately 45 percent lower for unemployment or inactivity as the next event, compared to workers with the same next event not affiliated to the scheme. A possible explanation for the relative lower hazard (or higher time ratio) in case of employment change, is the lack of direct monetary benefits, as a decrease in opportunity costs is not immediately perceived.

Taking reduced employment duration as an indicator for higher labor market flexibility, these results suggest that the policy led to its desired outcome of tackling previously more rigid labor markets in Chile. UISA can therefore present an alternative for emerging and developing economies that seek to protect their workforce in times of unemployment and to improve labor market rigidities, while avoiding some problems related to unemployment insurance (e.g. high monitoring costs to reduce moral hazard). It is however important to keep in mind that only formal private sector employees are covered under this policy in Chile and that informal workers continue to be unprotected and excluded from any kind of unemployment protection (Sehnbruch 2004). While Chile has a relative large formal labor market, other developing countries present significantly higher proportions of informality, restricting this scheme to workers that already have access to often comprehensive social security rights.

This policy certainly presents an alternative design in unemployment protection for developing nations with limited financial and monitoring capacities, but could equally present an option for developed countries, for example as an additional component combined with unemployment insurance based on risk-pooling. Moral hazard has been widely reported. Depleting the individual savings account before receiving access to the common fund could present a possible approach to restrict misuse.

Based on the analysis, further topics are on the agenda in Chile: low female labor market participation, a high share of temporary and often precarious employment contracts, limited knowledge of UISA, and the rather low amount of benefits. Women and workers with a temporary contract show significant higher hazard rates of terminating employment throughout the analysis. While labor market flexibility increases the dynamic and productivity of labor, it could also lead to unstable labor relations, generating situations, where the more vulnerable workers cannot access benefits as they are unable to fulfill the minimal conditions. In the competing risk analysis it further shows that women have a lower hazard of changing into a new employment, but a higher hazard of becoming unemployed or inactive compared to men, hinting to a more traditional attitude towards female labor market participation. While limited knowledge of UISA does not have a significant impact on labor duration in my sample, it might still prevent a share of workers from receiving benefits. And although the new UISA scheme certainly increases overall benefits, total amounts continue to be low, leading to restricted consumption smoothing and a possible severe drop in household income during unemployment spells. 
Since the introduction of the UISA scheme in Chile about a decade ago, one reform has been implemented in May 2009. A first paper by Huneeus, Leiva, \& Micco (2012) assesses changes in job search behavior between workers who decide to use unemployment benefits compared to those who decide against it before and after the reform. Further research may therefore focus on a more detailed examination of the UISA design and in particular on reforms, for example on the effect of specific scheme requirements after which workers become eligible to withdraw accumulated benefits or receive access to the solidarity fund. Another interesting aspect for future research is the type and quality of jobs workers find after they change employment or after unemployment spells.

\section{Endnotes}

${ }^{1}$ For each completed year of employment, workers are entitled to one month severance pay with a maximum of eleven years.

${ }^{2}$ Article 161 of the labor code: dismissal due to company needs (economic reason or downsizing).

${ }^{3}$ See Section 3 (Severance pay and labor mobility - what do we know?) for a more detailed discussion on the effects of severance pay and on severance pay in Chile.

${ }^{4}$ Benefits were indexed to the minimum wage to reflect purchasing power; the observed minimum wage growth was however always below the average wage growth within the economy. This resulted in decreasing replacement rates over time: from 14.8 percent in 1985 to 6.3 percent in 1995 to 4.4 percent in 2001. Replacement rates increased to over 30 percent after UISA introduction compared to Social Security benefits (Ferrada 2010).

${ }^{5}$ These additional support programs were often uncoordinated and ineffective. For the workfare programs only minimum wages were paid, the discretionary design presented problems, and the rushed implementation in times of crisis led to suboptimal program design. The hiring subsidies in times of high unemployment, in turn, were expensive (about USD 60 million), and abuse of the program was widely reported. Unemployment insurance for domestic helpers only covered this small sector of domestic employees, and job search assistance was only performed at the local level leading to limited geographical coverage (Acevedo, Eskenasi, \& Pagés 2006).

${ }^{6}$ In my sample only 5 workers who started in the year before UISA introduction changed to the new system, presenting below 0.5 percent of the sample. I excluded these workers from my analysis. Huneeus, Leiva, \& Micco (2012) report 2 percent voluntary affiliation by December 2010 in their paper.

${ }^{7}$ Since a reform in May 2009 workers with temporary contracts are also eligible to receive unemployment benefits through the solidarity pillar. The paper by Huneeus, Leiva, \& Micco (2012) describes the 2009 reform in more detail.

${ }^{8}$ Additional file 1 includes two figures with an overview of the financing of the Chilean UISA scheme.

${ }^{9}$ Also in case of just cause, including the following events: expiration of contract, voluntary resignation, or misconduct.

${ }^{10}$ Cross-country evidence, among others: Boeri \& Garibaldi (2009), Gomez-Salvador, Messina, \& Vallanti (2004), Messina \& Vallanti (2007). 
${ }^{11}$ Among others: Haffner et al. (2001), Heckman \& Pagés (2000), Haltiwanger, Scarpetta and Vodopivec (2003).

${ }^{12}$ For a more extensive literature overview on severance pay, see also Holzman et al. (2011).

${ }^{13}$ In my sample only 56 percent of workers received severance pay if employment was terminated by economic necessities or a shutdown of the firm. Before the introduction of UISA 59 percent received severance pay compared to 51 percent after the policy introduction. This difference is however not significant due to a low number of observations.

${ }^{14}$ Among others: Feldstein \& Altman (2007), Fölster (1999; 2001), Vodopivec (2010).

${ }^{15}$ They value the benefits to different extent, depending on risk aversion, gender and educational level, but always equal or more than its costs. The authors conduct an evaluation of worker's lifetime utility with and without UISA: lifetime consumption preferences of individuals are described with a constant absolute risk aversion (CARA), allowing them to smooth consumption while economically active.

${ }^{16}$ Database used: Administrative records of the contribution history and benefits paid to the workers affiliated to the unemployment benefit program by the Superintendencia de Pensiones.

${ }^{17}$ Encuesta de Protección Social in Spanish, or social protection survey.

${ }^{18}$ The survey is conducted by the Centre for Microdata, Department of Economics, of the University of Chile (Centro Microdatos, Universidad de Chile) with the support of the University of Pennsylvania.

${ }^{19}$ In each survey round three different types of questionnaires account for repeated, new and deceased participants.

${ }^{20}$ This binary variable is not a self-reported variable, nor does it include any information on benefit collection.

${ }^{21}$ Summary statistics of all variables in Additional file 1. See also Additional file 1 for the construction and definitions of these variables.

${ }^{22}$ On 30 September 2013: 1 USD = 505 CLP [www.xe.com].

${ }^{23}$ See also footnote 6: I exclude all workers who voluntarily changed to the new UISA scheme. Only 5 workers in my sample did so, representing less than 0.5 percent of the sample.

${ }^{24}$ Repeated spells: throughout the analysis I run the regressions by clustering the observations by their unique identifier. By specifying clusters the single observations are not considered independent, but the clusters defined. Due to repeated spells in the data set, I clustered the ID of the observations, as the same worker can be observed more than once since more than one job can be started during the two year period considered. It is reasonable to assume independence of individuals, but not within different observations of the same individual. Specifying the ID clusters in the regressions, I obtain robust standard errors. In case of observing intra-cluster correlations, the robust standard errors are better indicators for estimator variability, resulting in more accurate outcomes. Models with individual-level frailties (random-effect models in survival analysis) did not converge in the semi-parametric analysis.

${ }^{25}$ Separating the employment characteristics by UISA affiliation, the differences are not statistically significant, except for contract type, marginally significant at the 10 
percent level: while 54.6 percent find a permanent contract in their next employment relation if they are not affiliated to UISA, 48.5 percent find one if affiliated.

${ }^{26}$ In addition to the continuous time analysis, I run the regressions based on discrete time analysis and use the complementary log-log regression (the discrete-time proportional hazards model) to compare if results are similar: the cloglog regressions return qualitatively comparable results, where the UISA variable is statistically significant at a 1 percent level throughout the regressions and equally increases the hazard of leaving employment. Coefficients are quantitatively above the results of continuous time analysis, the difference is however minor.

${ }^{27} \mathrm{With}$ the logrank test I test the null hypothesis that the probability of employment survival of both groups is the same at any point of time. It compares the survival of both groups by taking the follow-up period into account (Bland \& Altman 2004). The Wilcoxon test is a rank test which places additional weight to earlier failure times than failures later in the distribution compared to the logrank test. In case the hazard functions are not proportional, this test is preferred over the logrank test (Cleves, Gutierrez, Gould, \& Marchenko 2010). I conduct both tests, as the proportionality assumption has not yet been tested.

${ }^{28}$ Figures not included in the paper, available upon request.

${ }^{29}$ Interactions tested: UISA*Female, UISA*Age, UISA*Temp. Contract, UISA*Education Dummies, UISA*Income Categories, UISA*Household Size, Female*Age, Female*Temp. Contract, Age*Temp. Contract, Temp. Contract"Hours, Temp. Contract"Income Categories, Temp. Contract"Household Size.

${ }^{30}$ See Additional file 1: Table S7.

${ }^{31}$ See Additional file 1: Table S8.

${ }^{32}$ I concentrate on the final model, as the AIC returns only marginally lower values for the interaction model. I additionally run the hazard functions with the interactions models, and the figures return qualitatively and quantitatively similar results.

${ }^{33}$ I exclude the interaction model to consolidate the competing-risk analysis.

${ }^{34}$ I concentrate on the coefficients of the final model.

${ }^{35}$ See Additional file 1: Table S9.

${ }^{36}$ See Additional file 1: Table S10.

${ }^{37}$ Unemployment statistics taken from the "Instituto Naticional de Estadística" (National Statistics Institute) [09.10.2013].

\section{Additional file}

Additional file 1: Appendix A: Overview UISA Scheme, Appendix B: Descriptive Statistics, Appendix C: Test of Proportional Hazards Assumption, Appendix D: Stratified Cox Model, Appendix E: Extended Sample, Appendix F: Control Group - Public Sector Employees.

Competing interests

The IZA Journal of Labor \& Development is committed to the IZA Guiding Principles of Research Integrity. The author declares that she has observed these principles. 
Received: 8 August 2013 Accepted: 24 October 2013

Published: 22 Nov 2013

\section{References}

Acemoglu D, Shimer R (2000) Productivity gains from unemployment insurance. Eur Econ Rev 44:1195-1224

Acevedo G, Eskenasi P, Pagés C (2006) Unemployment insurance in Chile: a new model of income support for unemployed workers. World Bank: Social Protection Discussion Paper, Washington DC

Akaike H (1974) A New look at the statistical model identification. IEEE Trans Auto Contr 19:716-723

Ata N, Sözer MT (2007) Cox regression models with nonproportional hazards applied to lung cancer survival data. Hecettepe Journal of Mathematics and Statistics 36(2):157-167

Berstein S, Contreras C, Benvin E (2008) Valoración del Seguro de Cesantía: Simulación de Beneficios con Datos Individuales. Serie Documentos de Trabajo, Superintendencia de Pensiones, Santiago de Chile

Berstein S, Fajnzylber E, Gana P (2012) The New Chilean unemployment insurance system: combining individual accounts and redistribution in an emerging economy. In: Holzmann R, Vodopivec M (eds) Reforming severance pay. World Bank, Washington DC, pp 259-284

Blanchard O (2000) The economics of unemployment. Shocks, institutions, and interactions. Lionel Robbins Lecture, London School of Economics, London

Bland M, Altman D (2004) The logrank test. BMJ 328:1073

Boeri T, Garibaldi P (2009) Beyond euroslerosis. Econ Policy 24(7):409-461

Box-Steffensmeier J, Jones B (2004) History modeling - a guide for social scientists. Cambridge University Press, Cambridge

Calmfors L, Holmlund B (2000) Unemployment and economic growth: a partial survey. Swedish Econ Policy Rev 7:107-153

Cleves M, Gutierrez R, Gould W, Marchenko Y (2010) An introduction to survival analysis using stata. Stata Press, College Station, Texas

Cox D (1972) Regression models and life-tables. J R Stat Soc 34(2):187-200

Cox D (1975) Partial likelihood. Biometrika 62(2):269-276

Feldstein M, Altman D (2007) Unemployment insurance savings accounts. Tax Policy Econ 21:35-63

Ferrada C (2010) Individual savings accounts in Chile. Income vs substituation effects and saving responses. University of Chicago, Chicago

Fölster S (1999) Social insurance based on personal savings. Econ Record 7:5-18

Fölster S (2001) An evaluation of social insurance savings accounts. Public Finance Manage 1:420-448

Gomez-Salvador R, Messina J, Vallanti G (2004) Gross job flows and institutions in Europe. Labour Econ 11(4):469-485

Haffner RN, Nicoletti G, Scarpetta S, Zoega G (2001) European integration, liberalization and labour market performance. In: Bertola G, Boeri T, Nicoletti G (eds) Welfare and employment in a United Europe. MIT Press, Boston, pp 147-250

Haltiwanger JS, Scarpetta S, Vodopivec M (2003) How institutions affect labor market outcomes: evidence from transition countries. Paper presented at the World Bank Economist Forum, Washington, DC

Heckman JJ, Pagés C (2000) The cost of Job security regulation: evidence from latin American labor markets. NBER Working Paper 7773, National Bureau of Economic Research, Cambridge, MA

Holzman R, Pouget $Y$, Vodopivec M, Weber M (2011) Severance pay programs around the world: history, rationale, status, and reforms. IZA Discussion Paper No, Bonn, p 5731

Hopenhayn H, Hatchondo JC (2012) The welfare consequences of alternative designs of unemployment insurance savings accounts. In: Holzman R, Vodopivec M (eds) Reforming severance pay. The World Bank, Washington DC, pp 239-257

Huneeus C, Leiva S, Micco A (2012) Unemployment insurance and search efforts in Chile. IDB Working Paper Series No. IDB-WP-313, Washington DC

Kugler A (2002) From severance pay to self-insurance: effects of severance payments savings accounts in Colombia. IZA Discussion Paper No, Bonn, p 434

Messina J, Vallanti G (2007) Job flow dynamics and firing restrictions: evidence from Europe. Econ J 117(521):279-301

Montenegro CE, Pagés C (2004) Who benefits from labor market regulations? Chile, 1960-1998. In: Heckmann JJ, Pagés C (eds) Law and employment: lessons from Latin America and the Caribbean. University of Chicago Press, Chicago, pp 401-434

Nickell S (1997) Unemployment and labor market rigidities: Europe versus North America. J Econ Perspect 11 No 3:55-74

Poblete I (2011) Análisis del Uso de Beneficios en el Seguro de Cesantía Chileno. Serie Documentos de Trabajo, Superintendencia de Pensiones, Santiago de Chile

Reyes G (2005) Duración de las Relaciones Laborales de los Afiliados al Seguro de Cesantía: Análisis y Problemas Metodológicos. Superintendencia de Administradoras de Fondos de Pensiones. Serie Documentos de Trabajo No, Santiago de Chile, p 11

Reyes G, van Ours JC, Vodopivec M (2011) Incentive effects of unemployment insurance savings accounts: evidence from Chile. Labour Economics 18:798-809

Rodríguez G (2010) Parametric survival models. Princeton University, Lecture Notes

Sehnbruch K (2004) Privatized unemployment insurance. Can Chile's New unemployment insurance scheme serve as a model for other developing countries? Center for Latin American Studies, University of California, Berkeley

Sehnbruch K (2006) Unemployment insurance or individual savings accounts: Can Chile's New scheme serve as a model for other developing countries? Int Soc Secur Rev 59(1):27-48

Vodopivec M (2004) Income support for the unemployed: issues and options. Regional and Sectoral Studies Series, The World Bank, Washington, DC

Vodopivec M (2010) How viable are unemployment insurance savings accounts: simulation results for Slovenia. Comp Econ Stud 52:225-247

Vodopivec M (2013) Introducing unemployment insurance to developing countries. IZA Journal of Labor Policy 2:1

Wulfgramm M, Fervers L (2013) Unemployment and subsequent employment stability: does Labour market policy matter? IZA discussion paper No. 7193. Institute for the Study of Labor, Bonn

10.1186/2193-9020-2-9

Cite this article as: Nagler: How unemployment insurance savings accounts affect employment duration: evidence from Chile. IZA Journal of Labor \& Development 2013, 2:9 